\title{
UM VOO EM PARCERIA: ARTICULAÇÃO DESIGN, ACADEMIA E SETOR PÚBLICO NO RIO DE JANEIRO
}

Luiz Antonio dos Santos Barros

Pontifícia Universidade Católica do Rio de Janeiro PUC-Rio

luizbarros13@yahoo.com.br

Claudio Freitas de Magalhães, Dr

Pontifícia Universidade Católica do Rio de Janeiro PUC-Rio

claudio-design@puc-rio.br

Resumo: Esse artigo aborda a experiência da superintendência de design da Secretaria de Desenvolvimento Econômico do Estado do Rio de Janeiro, e coordenadoria das mostras Rio+Design, no Rio de Janeiro e em Milão Itália, e do trabalho em parceria com novos e consagrados designers cariocas. Procede também da indagação em verificar se os escritórios de design do Rio de Janeiro são promotores da atividade e dos benefícios do design para o desenvolvimento econômico do Estado do Rio de Janeiro. Nesse texto abordamos o surgimento das indústrias criativas; a importância e desafios da economia criativa no Rio de Janeiro; a crescente relevância e premiações nacionais e internacionais dos designers cariocas; o programa Rio é Design e as mostras Rio+Design; e, por fim, demonstramos um case da articulação e parceria entre designers, academia e setor publico na promoção e divulgação da grande abrangência e dos benefícios do design. O artigo apresenta o projeto do NEXT - Núcleo de Experimentação Tridimensional do Departamento de design da PUC-Rio "Voando ao redor do Cristo", exposto na mostra Rio + Design Milão 2015. O artigo apresenta como resultado que a união do conhecimento compartilhado das capacitações dos designers cariocas, das redes de relacionamento, do apoio do governo do estado cria os valores imateriais do design carioca promovendo o fortalecimento da atividade de design no Estado do Rio de Janeiro.

Palavras-chave: indústria criativa, parcerias no design, escritórios de design, projeto Rio+Design.

\begin{abstract}
This article discusses the experience of oversight of design of the Secretariat of Economic Development of the State of Rio de Janeiro, and coordinating body shows Rio + Design, in Rio de Janeiro and Milan - Italy, and work in partnership with new and established Rio designers. Proceeds also the question of verifying that the design offices of Rio de Janeiro are promoters of the activity and the benefits of design for economic development of the State of Rio de Janeiro. In this text we discuss the
\end{abstract}


emergence of the creative industries; the importance and challenges of the creative economy in Rio de Janeiro; the growing relevance and national and international awards of Rio designers; Rio program is Design and Rio + Design shows; and finally, we demonstrate one case the joint and partnership between designers, academia and the public sector in the promotion and dissemination of broad scope and benefits of the design. The article presents the NEXT project - Dimensional Experimentation Center of the Department of PUC-Rio design "Flying around the Christ", exposed at Rio + Design Milan 2015 shows. The article presents the result that the union of shared knowledge of the capabilities of Rio designers of social networks, state government support create the intangible values of Rio's design to promote the strengthening of design activity in the State of Rio de Janeiro.

Keywords: creative industry, partnerships in design, design offices, Rio + Design project.

\section{INTRODUÇÃO}

A partir da década de 80, percebe-se que a importância da criatividade no contexto da economia, não se limitava mais apenas aos bens e serviços culturais, abrangendo também as indústrias de bens ordinários como, por exemplo, o design. Essa percepção originou um fórum de discussão, empreendido pelo governo britânico, para eleger a criatividade como foco do planejamento econômico daquela nação, criando-se a partir daí o conceito "indústrias criativas", definidas como aquelas que têm origem em criatividade, habilidade e talentos individuais, e demonstram potencial para gerar emprego e renda através da propriedade intelectual (Council, 2007). Nessa direção podemos observar que países com economia competitiva, como o Reino Unido, passaram a priorizar a economia criativa e, dessa forma, apoiar ações de promoção do design, da inovação e da tecnologia com o objetivo de tornar competitiva as suas economias em face do mercado consumidor global.

O tema indústria criativa vem ganhando importância - sobretudo a partir da legitimação da geração de alto valor agregado a toda a sua cadeia produtiva - e se fortalecendo no âmbito da ciência econômica, especialmente o campo de estudos da economia da cultura. São fatores determinantes para o reconhecimento da importância da economia da cultura: a revitalização e mudança de fluxos de renda e emprego; a necessidade de avaliação dos bens culturais; e os desafios teóricos de compreensão de um novo campo de conhecimento (Benhamou, 2007).

A associação de fatores culturais ao desenvolvimento econômico evidencia cada vez mais a relevância de valores, costumes, redes sociais, instituições formais e informais para o desenvolvimento de uma localidade. Nesse sentido, as atividades de um grupo também podem ser classificadas como culturais, quando possuem alguma forma de criatividade em suas relações e produções, geram ou comunicam conteúdos simbólicos, e seus produtos devem ter a possibilidade de adquirir propriedade intelectual (Throsby, 2005). 
Nesse contexto, a economia criativa induziu às instituições e corporações a valorizar a criatividade e a inovação, bem como a aliar o pensamento racional econômico ao intuitivo e criativo, característica da formação e do processo de desenvolvimento do design. Nesse panorama o design deixa de estar relacionado apenas à etapa final de desenvolvimento de um produto, com a missão superficial meramente de embelezamento (styling). O design passou a ser visto também como atividade transversal, participando de todas as etapas produtivas, valorizando objetos e serviços, a partir da associação da inteligência criativa e multidisciplinar dos designers às diversas fases das diferentes cadeias produtivas.

O quadro (Firjan, 2010) a seguir demonstra a colocação destacada do Estado do Rio de Janeiro, em primeiro lugar, quanto à média de remuneração dos profissionais da indústria criativa em relação ao cenário nacional.

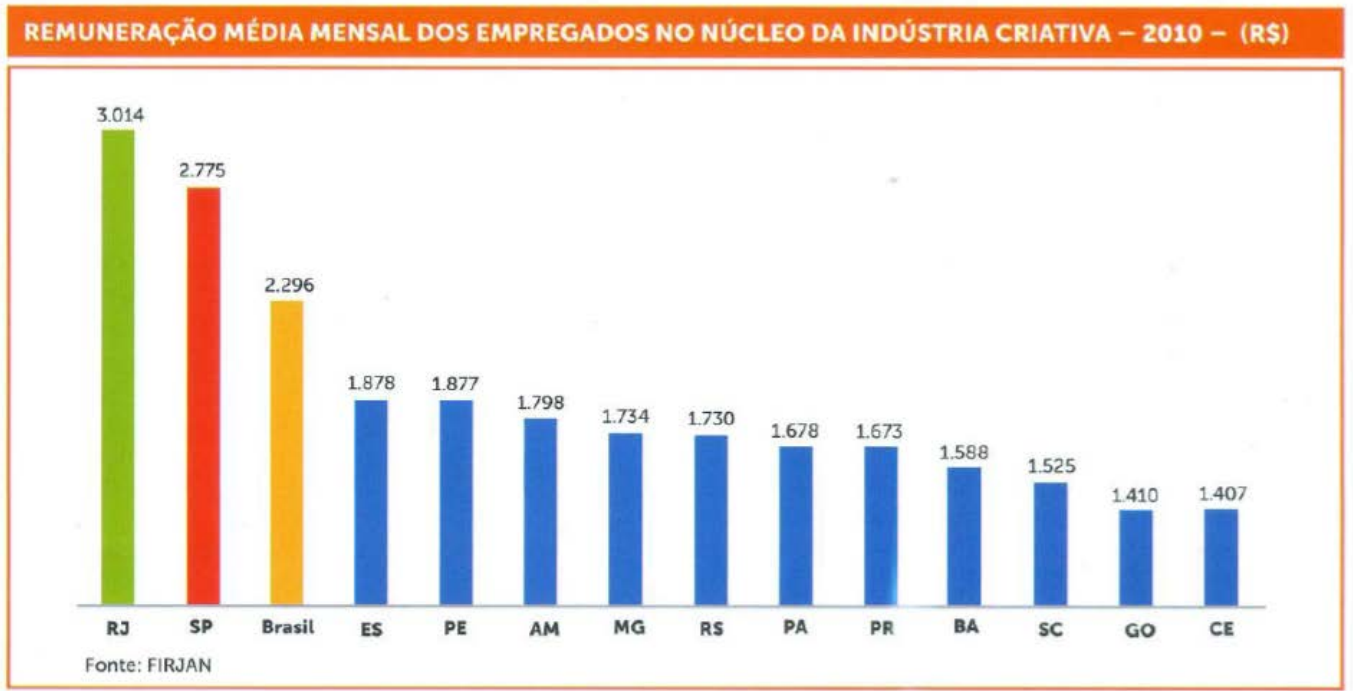

Quadro 1 - Remuneração na indústria criativa (FIRJAN, 2010)

No entanto, o potencial e a qualidade do design muitas vezes premiado produzido no Estado do Rio de Janeiro podem não estar sendo absorvidos e valorizados adequadamente pelos setores produtivos fluminenses. De fato, designers cariocas vêm atuando com crescente sucesso, sobretudo aqueles voltados para o design de mobiliário, em estados da região sul do país, em que o campo do design é cada vez mais valorizado como diferencial produtivo pelas empresas lá instaladas.

Por causa disso, atualmente muitos designers do Rio de Janeiro produzem suas peças no estado do Rio Grande do Sul, onde as empresas moveleiras estão bem equipadas tecnologicamente, e abertas a investir em especificações diferenciadas para produtos. No entanto, nos últimos anos observamos uma retomada de crescimento da indústria moveleira fluminense, agora formando parcerias com o setor de design do estado.

\section{DESENVOLVIMENTO}

\subsection{Valores intangíveis}

Nesse novo cenário a noção de produto vem sendo rapidamente alterada pela agregação de valores intangíveis aos fatores físicos ou tangíveis, ou seja, pela inclusão 
de tecnologia, design, inovação, articulação de parcerias, marcas e patentes, marketing, governanças corporativas e lideranças locais (Fingerl, 2004).

E o que é o valor intangível? O intangível é uma mescla de competências individuais (conhecimento e capacitações), competências organizacionais (base de dados, tecnologias, rotinas e cultura empresariais) e relacionais (redes de relacionamentos, reputação), que embora não reconhecidas na visão contábil tradicional, são identificadas como ativos por investidores, acionistas, fornecedores e clientes. (OCDE, 2005). Os ativos intangíveis possibilitam a valorização e a diferenciação das organizações junto ao mercado, podendo ser divididos em quatro categorias básicas - estrutural, intelectual, relacional e ambiental (Fingerl, 2004).

Sendo assim o valor real atual das empresas passou a não estar mais presente apenas no balanço contábil, que só relaciona os ativos tradicionais das corporações, como máquinário, estoques, edificações, volume de vendas, por exemplo. Outra parte desse valor passou a incluir no conjunto de ativos que os balanços das empresas não conseguem exprimir, os valores intangíveis. E é nesses valores impalpáveis que encontraremos o diferencial das empresas e instituições, pois só dessa maneira as corporações poderão evoluir e se manter no mercado, atual e futuro.

Portanto, os valores imateriais e intangíveis passam a ser os verdadeiros motores de um novo cenário que inclui marcas, talentos, reputação, conhecimento, relacionamentos, tecnologia, patentes, inovação, sustentabilidade e governança.

$O$ valor intangível também pode ser caracterizado como uma propriedade das organizações, das pessoas e dos países, que emerge quando existem articulações entre vários atores. Trata-se de valor que brota de um conjunto estruturado de alguma organização, instituição ou grupo de pessoas que compartilham conhecimentos complementares e interesses comuns.

\subsection{Inovação e design}

As particularidades da economia brasileira levaram as empresas privadas a um alto patamar de informalidade, a um baixo grau de inovação e de investimento tecnológico, à inadequação de mecanismos financeiros e de garantias exigidas com foco na inovação, e, principalmente, a fraca articulação entre as diversas instâncias que atuam sobre a inovação, como setor público, setor privado, universidades e institutos de pesquisas (Fingerl, 2004).

Enfrentamos no Brasil o desafio da busca de um novo estágio de desenvolvimento em que os fatores intangíveis tenham o papel central. Contudo, existe também o risco devido a possibilidade de perder a corrida para outros países, que vêm enfrentando a mudança desse novo modelo de desenvolvimento com base na valorização do capital intangível, com políticas públicas abrangentes e com grande participação do setor privado (Velloso, 2002).

Sendo assim é necessário para o país o fortalecimento e a continuidade de um elenco de empresas e instituições capazes de investir e desenvolver tecnologia e exportar produtos com maior valor agregado. Trata-se da escolha entre crescimento e desenvolvimento, este apoiado na diferenciação, na mudança estrutural dos ativos das empresas, incorporando os novos parâmetros de natureza intangível. E a disputa no mercado externo, já saciado de espaços e de produtos semelhantes, só pode ser feita através da criatividade, inovação, design e marketing (Deutscher, 2008). 
Essa nova realidade passa a exigir também dos governos nacional, estaduais e municipais a elaboração de diretrizes de políticas públicas com foco na inovação e na diferenciação. Nesse contexto o design tem possibilidade de desempenhar papel determinante, como ponte para a construção ou a ressignificação de setores diversos: economia, tecnologia, cultura, social, meio ambiente entre outros. Os designers podem ter papel significativo na busca de soluções para diferentes problemas dos consumidores, podendo ser a solução para um problema social, a saída lucrativa para um problema de negócios ou o recurso de integração para uma nova tecnologia (Leite, 2010).

Através do desenvolvimento de projetos, do pensamento e da formação multidisciplinar dos designers, o design reforça a inovação e é potencial ferramenta para as organizações em um mercado competitivo que se reinventa constantemente. Numa época de mudanças permanentes, o processo criativo no desenvolvimento dos projetos de design, com a criação focada na experiência dos usuários, análise de realidades imediatas e complementares, simulação de cenários futuros possíveis e prototipagem rápida, cada vez mais refinada para testes de possíveis soluções, encurtam-se as etapas de produção e, dessa forma, protegem-se e se aceleraram as inovações das empresas (Leite, 2010).

\subsection{Vocação do Rio de Janeiro para o design}

Certas vocações cariocas são famosas, como esporte, diversão, ensino, pesquisa, cultura boemia. Ha outras, porem, menos conhecidas, mas igualmente simbólicas para a história e a economia desta cidade. Design e uma delas (Redig in Leite, 2003).

E em qual estagio de desenvolvimento está o design produzido no Rio de Janeiro, nesse cenário que caminha para a valorização do capital intangível? O Rio de Janeiro é o lócus ideal no Brasil para o fortalecimento do design focado no futuro, na formulação de novos produtos e serviços e, principalmente, novos processos.

Como pólo central da indústria criativa brasileira - que inclui aspectos tão diversificados como televisões, indústria fonográfica, bossa nova, editoras, produção cinematográfica e teatral, atores residentes, grande desfile das escolas de samba, renascimento do carnaval de rua, reveillon, grandes eventos de música - a cidade é o ambiente privilegiado para o fortalecimento e para a representatividade do design dentro da indústria criativa nacional (Patrocínio, 2009).

O Rio de Janeiro pode caracterizar-se pela vocação natural para o design, uma cidade que "respira" design, porque abriga institutos de pesquisa com direcionamento para o design; incubadoras de design; centros de excelência em marketing; escritórios e agências de design premiados nacional e internacionalmente, abrangendo todas as especialidades da área.

É preciso ressaltar ainda que a cidade é pioneira no ensino de design brasileiro, precursora nos cursos de mestrado e doutorado da área, com escolas de relevância nacional. Essas escolas formam significativo número de profissionais, os quais estabelecem escritórios na cidade, tornando-a expoente da produção do design brasileiro. Além disso, muito desses profissionais são convidados a trabalhar e lecionar em outros estados e países, exportando, dessa maneira, o DNA carioca e o processo de desenvolvimento de design dos profissionais formados na cidade (Naveiro in Senna, 2009). 
Já no setor público e no campo da pesquisa o Estado do Rio de Janeiro concentra várias entidades com direcionamento para o design, tais como: Governo do Estado do Rio de Janeiro, Prefeitura da Cidade do Rio de Janeiro, Instituto Nacional de Tecnologia - INT, Federação das Indústrias do Estado do Rio de Janeiro - Firjan, Serviço de Apoio às Micro e Pequenas Empresas-Sebrae-RJ, Rede de Tecnologia - Redetec, Incubadoras de Design entre outras.

Antropólogos e economistas assinalam as particularidades do Rio de Janeiro como capital cultural nacional. É a cidade de referência internacional do Brasil e, concentra, principalmente através dos polos de comunicação aqui instalados, os principais formadores de opinião nacional (Velho, 2007), tendo grande potencial para se tornar, em futuro muito próximo, a capital da indústria criativa do país (Urani, 2008).

\subsection{Designers e desenvolvimento local no Rio de Janeiro}

Nesse panorama é possível enxergar novas demandas e novos negócios para o design, impulsionando o crescimento das empresas cariocas do ramo e ajudando a promover, mediante maior participação dos profissionais de design junto aos setores produtivo e público, o desenvolvimento local do estado.

Nesse sentido, a interface de interação do design e dos setores produtivos do estado requer ações efetivas, que integrem o processo de desenvolvimento da atividade de design, à política de promoção da vantagem competitiva de produtos e serviços, através do incentivo a novos serviços em design, com foco no desenvolvimento local.

No Estado do Rio de Janeiro, e também no país, a interface do design com os setores público e privado carece de avaliação; falta também continuidade de políticas de promoção de novos serviços em design. Nesse sentido, destaca-se a função dos designers do Rio de Janeiro como indutores da promoção da atividade do design, bem como do maior conhecimento dos benefícios do design junto aos setores produtivos do estado, partindo da proposição de que a ação efetiva dos designers promove o desenvolvimento local do estado.

Estima-se que haja mais de 1000 profissionais autônomos e cerca de 500 escritórios de pequeno porte e alguns de médio porte (Patrocínio, 2009). O reconhecimento à qualidade do design produzido por esses e escritórios tem-se refletido na significativa quantidade de importantes premiações, nacionais e internacionais, de design recebidas por projetos e produtos desenvolvidos nas mais variadas áreas de atuação do design. Dentre os prêmios de referência no campo do design recebidos por esses profissionais destacam-se: IF Designer Hannover; IDEA Brasil e Internacional; Salão Design Casa Brasil; Design Móvelsul; Museu Casa Brasileira e TOP XXI - Mercado Design.

As premiações conquistadas nos últimos anos, em escala inédita, atestam a qualidade profissional e o diferencial do design produzido no Rio de Janeiro. Ressaltase que o design contemporâneo do Rio de Janeiro conversa com o design internacional, através do intercâmbio de designers e de projetos (Senna, 2009). A constatação de que os designers e escritórios de design cariocas formam uma grande rede de fomento do design do Rio de Janeiro justificam o cenário atual da participação 
e do fomento ao design no Estado do Rio de Janeiro, a partir da ação desses agentes junto ao setor publico.

Com esse direcionamento abordamos os designers e escritórios cariocas de design, com seus processos de trabalho e de articulação com os setores produtivo e público, como importantes objetos de estudo para a promoção do desenvolvimento local através do design. Consideramos sua produção a tradução do design contemporâneo produzido no Rio de Janeiro, bem como sua visibilidade e o seu reconhecimento. É importante lembrar o papel atual de articulação desses profissionais como fator fundamental de inovação para o setor de design no Estado, junto aos setores produtivos, governamentais e da mídia.

\subsection{Programa Rio é Design, Conselho de Design e mostras Rio+Design}

O Governo do Estado do Rio de Janeiro reconhece o valor do design como elemento importante para alavancagem do desenvolvimento econômico. Tem realizado diversas ações no sentido de fomentar o investimento em design pelas empresas do estado, na busca de uma produção de maior valor e qualidade. Criou, na estrutura da Secretaria de Desenvolvimento Econômico, uma Coordenação responsável por articular esses esforços, além de instituir um Conselho Consultivo de Design, composto por alguns dos principais nomes do design do Rio de Janeiro (Estrada, 2010).

O Programa Rio é Design, do governo do Estado do Rio de Janeiro, trabalha com foco no papel estratégico da Secretaria de Estado de Desenvolvimento Econômico SEDEIS de articulação e fomento do desenvolvimento econômico, buscando auxiliar na promoção da competitividade das empresas cariocas de design e do setor produtivo fluminense. Criado em 15/01/2007 pelo decreto 41.127 (Rio de Janeiro, 2007a), o programa Rio é Design conta com a assessoria do Conselho Consultivo de design constituído em 22/05/2007 pela Resolução 012 (Rio de Janeiro, 2007b) e composto por renomados designers da iniciativa privada, da academia e das associações profissionais do setor, além de representantes de empresas e entidades públicas e privadas.

As ações do programa Rio é Design se correlacionam com as estratégias da SEDEIS de promoção do desenvolvimento econômico através da melhoria do ambiente de negócios; da articulação do poder de compra; do desenvolvimento tecnológico e inovação; do desenvolvimento regional e de arranjos produtivos locais.

O apoio ao desenvolvimento tecnológico e inovação tem como objetivo propiciar uma melhoria no ambiente de negócios. A existência de um vasto ativo constituído de universidades públicas e privadas, centros de pesquisa, entidades federais como o Instituto Nacional de Metrologia, Qualidade e Tecnologia - Inmetro, o Instituto Nacional de Tecnologia - INT e o Instituto Nacional de Propriedade Industrial - INIPI, dão ao Estado do Rio de Janeiro amplas possibilidades para ser referência nacional no Sistema de Ciência e Tecnologia (Bueno, 2007).

Trabalhando na promoção do design como ferramenta estratégica para associar valor e qualidade aos produtos e serviços produzidos no estado, o programa atua através de diversas ações. Uma das ações em destaque é a Rio+Design, evento semestral coordenado pela Secretaria de Desenvolvimento Econômico, com uma edição nacional e outra internacional, que vem a cada edição acrescentando mais parceiros, entre designers, universitários, empresários e instituições de apoio, com o 
objetivo de divulgar e demonstrar o potencial do design na promoção do desenvolvimento local do estado.

A Rio+Design teve sua primeira edição em setembro de 2008, paralelamente a 1ạ Brazil Design Week, realizada no Museu de Arte Moderna do Rio de Janeiro - MAM, com o apoio do governo do Estado do Rio de Janeiro. Desde a sua criação a Rio+Design mobilizou grandes nomes do design e marcas cariocas. Exposições, seminários, visitas a escritórios e universidades de design, eventos e atividades aconteceram simultaneamente junto ao comércio e instituições direcionadas para essa área, traduzindo a adesão à iniciativa e o potencial do Rio de janeiro como polo criativo de design no país. Em 2009 a Rio+Design fez sua primeira exposição em Milão - Itália.

\subsection{Case da articulação universidade e poder público.}

Dentre os parceiros do programa de design da Secretaria de Desenvolvimento Econômico destaca-se o Departamento de Design da PUC-Rio, que participa com projetos diversos nas edições da mostra Rio+Design, coordenada pela SEDEIS em parceria com a FIRJAN, SEBRAE e demais parceiros.

Citada pelo coordenador do NEXT PUC-Rio como um exemplo da articulação da universidade com o poder público, a Rio+Design é uma ação da Secretaria de Desenvolvimento Econômico do Estado do Rio de Janeiro, que consiste na mostra das mais recentes produções e peças dos designers cariocas. Com quatorze edições já realizadas a mostra vem se consolidando como uma importante vitrine da produção mais recente do design do estado.

Anualmente o programa de design do governo do Rio de Janeiro realiza duas mostras Rio+Design, em âmbito nacional e internacional, no primeiro semestre em Milão, simultaneamente ao Salão Internacional do Móvel. No segundo semestre a exposição é apresentada durante a Semana Design Rio, no Jockey Club Brasileiro. Esse ano a edição internacional, a Rio+Design Milão 2015, recebeu 50 mil visitantes atingindo o recorde de público em todas as edições já realizadas, já que o recorde de público nacional, de 15 mil pessoas, foi alcançado na Rio+Design 2014 realizada em novembro último.

O Laboratório NEXT (Núcleo de Experimentação Tridimensional) da PUC-Rio apresentou, durante a Rio+Design Milão 2015, o projeto "Voando ao redor do Cristo Redentor" (Massarotto, 2015). Tratou-se de uma experiência virtual única, que permitiu ao público, pela primeira vez, literalmente voar junto ao monumento que é o símbolo do Rio de Janeiro e do Brasil no mundo, eleito recentemente uma das sete maravilhas do mundo moderno. O voo foi possível a partir do escaneamento do Cristo realizado por drones equipados com câmeras. As imagens obtidas foram processadas por softwares da pix4D gerando o primeiro arquivo digital preciso da imagem do Cristo. Este arquivo foi então editado pela BL3ND e o voo programado pelo Tecgraf.

Na sequência de imagens a seguir, podemos ver fila de pessoas aguardando a vez para o voo virtual ao redor do Cristo, e o embaixador do Brasil em Milão recebendo orientações para o seu voo virtual ao Cristo Redentor. Por último, grupo de designers expositores da Rio+Design 2015 presentes em Milão. 

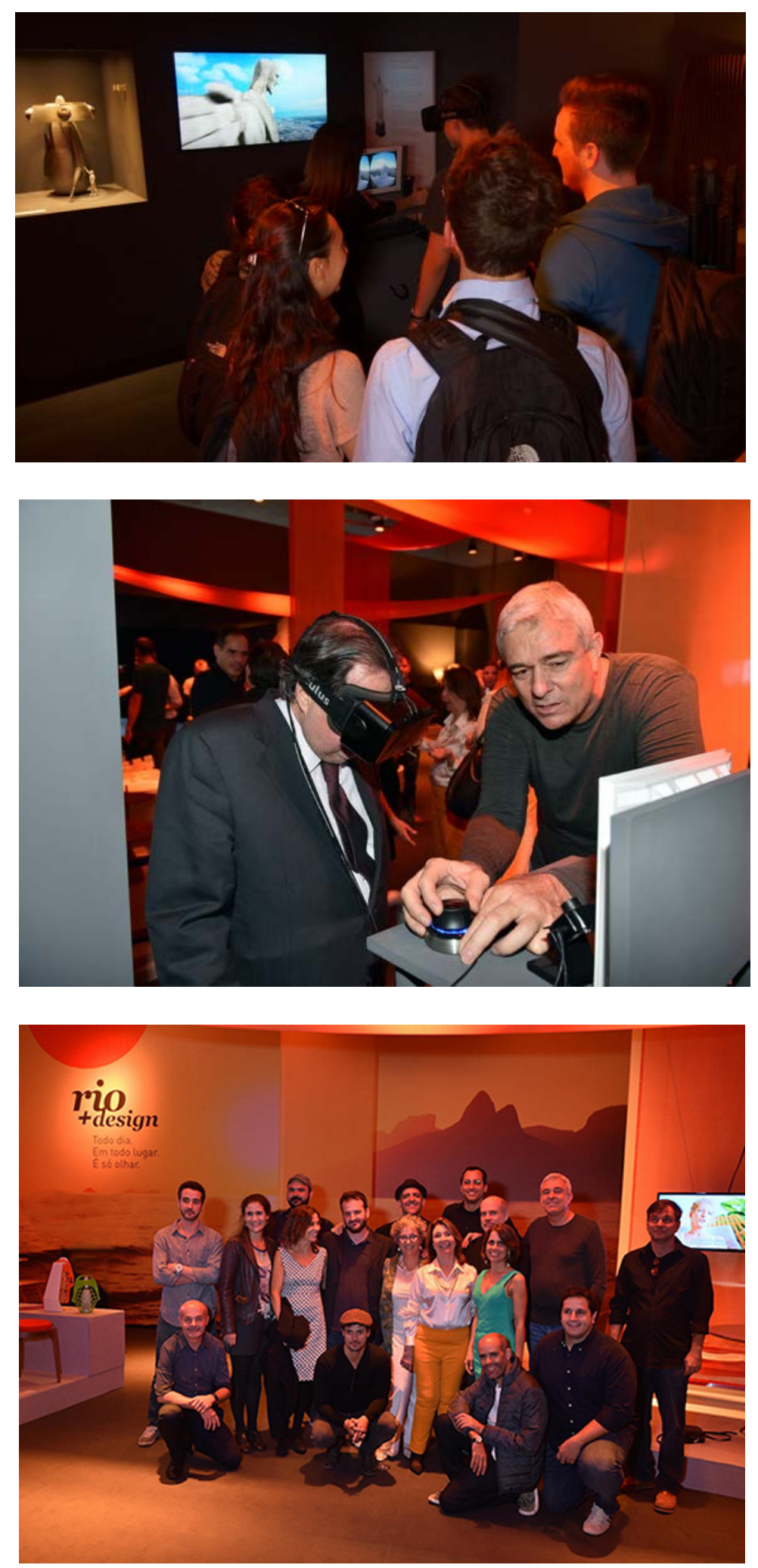

A recepção das pessoas foi simplesmente espetacular. Desde o primeiro dia, formaram-se filas para experimentar o voo: as pessoas se moviam, esticavam a mão para tocar o Cristo e até ficavam com receio de olhar para baixo. A experiência deixava todos encantados com a possibilidade de se aproximar do mais famoso monumento brasileiro

(Celso Santos in HTTPS://www.facebook.com/riomaisdesign) 
A Rio+Design Milão 2015 reuniu, além do projeto "Voo virtual ao redor do Cristo" 43 empresas cariocas de design apresentando 80 projetos. Foram contabilizadas 160 matérias: 20 em jornais, 10 em revistas e 130 em portais, dentre eles: Globonews, O Estado de são Paulo, Folha de São Paulo, O Globo, Revista O Globo, O Dia, O Fluminense, Jornal do Comércio, G1, Brasil Econômico, Casa Vogue, Casa Claudia e Casa e Jardim. Foram realizadas também 7 entrevistas e coberturas de 4 canais de TV nacionais e internacionais.

Como observou o diretor do Departamento de Design da PUC-Rio a participação do departamento na Rio+Design Milão 2015, através do NEXT, demonstra que a tecnologia é um excelente modo de ampliar as possibilidades de colaboração do design com a sociedade.

\section{CONSIDERAÇÕES FINAIS}

O designer Felipe Rangel, do Estúdio Baobá, formado em design de produtos pela PUC-Rio, lembra que o Rio era uma grande referência no desenho e na fabricação de moveis nos anos 50 e 60. Para ele, o setor tem crescido significativamente nos últimos anos: - A cidade é uma capital criativa e está cada vez mais forte no setor moveleiro. Hoje temos eventos como o Rio+Design que divulga o design carioca (Cândida, 2015).

A parceria entre designers, academia, setores publico e privado no Rio de Janeiro promove o design carioca, tanto em âmbito nacional quanto na esfera internacional. Com o fortalecimento da indústria criativa no Rio de Janeiro, com as premiações de muitos designers do estado e com o crescente publico das mostras Rio+Design, os benefícios e a abrangência do design passaram a ter maior visibilidade do publico e atenção da mídia.

As associações entre profissionais, redes sociais, instituições, indústrias, academia e poder publico no Rio de Janeiro evidenciam essas parcerias como importantes formas de incentivo ao desenvolvimento do design carioca. Nesse panorama, as lideranças e governanças públicas e privadas agregam valor aos serviços e produtos do design, auxiliando na promoção do desenvolvimento local no estado. Assim, a ideia de produto passa a ser modificada com a associação do valor intangível através da inclusão junto ao design, da tecnologia, do marketing, da inovação, da articulação de parcerias, das lideranças setoriais e das governanças locais.

A união do conhecimento compartilhado, das capacitações e reputações dos designers cariocas, das redes de relacionamento que se fortalecem, além da iniciativa e apoio do governo do estado, formam os valores imateriais do design carioca trazendo resultados positivos, para o desenvolvimento da atividade e para a economia do Estado do Rio de Janeiro.

A exibição do projeto "Voando ao redor do Cristo", além de apresentar a associação do design com a alta tecnologia, demonstrou a pluralidade do design e a formação multidisciplinar dos profissionais desta área, exemplificando uma das possíveis alianças e articulações no vasto campo do design. 


\section{REFERÊNCIAS}

BENHAMOU, F. A economia da cultura. Cotia - SP: Atelier Editorial, 2007.

BUENO, J. C. C. Polos de desenvolvimento do Estado do Rio de Janeiro. In XIX Fórum Nacional. Anais Instituto Nacional de Altos estudos - INAE: Série Estudos e Pesquisas No 180, 14-17 maio 2007.

CANDIDA, S. Mãos que dão vida a formas inovadoras. Jornal O Globo, Rio de Janeiro, 28 jun. 2015. Primeiro caderno, p.16.

COUNCIL, Design. The Good Design Plan. National strategy and Design Coucil delivery plan 2008 - 11. London, 2007.

ESTRADA, M. H. O vai-e-vem do design. São Paulo: Editora Roma. Revista Arc Design, No. 67, Agosto 2009.

LEITE, J. S. A herança do olhar: o design de Aloisio Magalhaes. Rio de Janeiro: Artviva, 2003

LEITE, R. Ver e compreender: design como ferramenta estratégica de negocio. Rio de Janeiro: Ed. SENAC Rio, 2010.

MASSAROTTO, F. O Cristo Redentor desembarca no Salão do Móvel. Jornal O Globo, Rio de Janeiro: 18 abr. 2015. Segundo Caderno, capa.

OCDE. Manual de Oslo. Diretrizes para a coleta e interpretação de dados sobre inovação. OCDE / FINEP, 2005.

PATROCINIO, G. Conceituando a Rio International Design Week. Rio de Janeiro, Conselho Consultivo de Design. Julho, 2009.

RIO DE JANEIRO (Estado). Decreto 41.127 de 15 de janeiro de 2007. Dispõe sobre o programa de promoção e apoio ao Design no Estado do Rio de Janeiro - Rio é Design. Rio de Janeiro, E-11/609/2007.

RIO DE JANEIRO (Estado). Resolução SEDEIS No. 012 de 22 de maio de 2007. Constitui o Conselho Consultivo do Programa Rio e Design para fins que menciona. Rio de Janeiro, E-11/466/2007.

SENNA, B. (Org.) Continum: design contemporâneo do Rio de Janeiro. Rio de Janeiro: Viana \& Mosley, 2009

THROSBY, A. J. On Hollywood: the place, the industry. Nova Jersey: Princeton University Press, 2005.

URANI, A. Trilhas para o Rio: do reconhecimento da queda a reinvenção do futuro. Rio de Janeiro: Elsevier, 2008.

VELLOSO, J. P. R. Brasil e a Economia do Conhecimento. Rio de Janeiro: J. Olympio, 2002.

Mostra leva o design carioca para o Salão do Móvel de Milão, na Itália.

HTTP://globotv.globo.com/globo-news/jornal-das-dez/v/designers-cariocas-expoempecas-em-evento-na-italia/4083018/

Projeto permite fazer voo virtual 3D ao Cristo Redentor - G1 Online 
HTTP://globo.com/G1

$18 / 04 / 2015$

Tecnologia é destaque na mostra Rio+Design 2015 em Milão.

WWW.ofluminense.com.br/editoriais/cultura-e-lazer $25 / 02 / 2015$ 